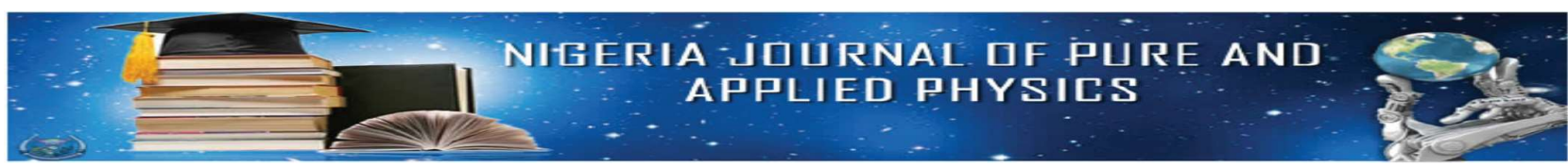

Nigeria Journal of Pure \& Applied Physics, Vol. 8, No. 1, pages 40-47, 2018

\title{
Relevance of Computation Techniques in Materials Development - A Review
}

\author{
Popoola, A.I. \\ Department of Physics, \\ Federal University of Technology Akure, NIGERIA. \\ email: ispopoola71@gmail.com; aipopoola@futa.edu.ng.
}

\begin{abstract}
Experimental investigation was the sole technique in the early years of material science and engineering. High investigation cost and delay in timely delivery of end products had militated against experimental technique. The development of quantum and statistical mechanics led to a powerful computation technique that had effectively complement experimental investigation efforts. The computation technique has predicted a number of new materials, with some already synthesized. The use of computation techniques cuts across all areas of materials science and engineering. The capabilities of available computation techniques are reviewed with emphasis on strong intermetallic compounds.
\end{abstract}

Keywords: ab initio, molecular dynamics, ductile, density of states, elastic constants

\section{INTRODUCTION}

A material can be defined as any substance intended for a particular purpose. Our deeper insight in the field of chemistry and physics has largely spurred major material discovery efforts. The various advancements in science and technology would have remained a mirage if not for the various milestone achievements in materials science and engineering. Noteworthy, is the improvement in human life and its consistent progress since the discovery of bronze, iron and up to this silicon age. Advances in materials development and synthesis have tremendously impacted on human history with a lot of economic prosperity.

The need for a wider range of materials with specialized properties can't be over-emphasized. The greenhouse gas emissions concern requires materials that are reliable and environmental friendly. Thus, the need for new class of materials of unprecedented functionality has become expedient. Theoretical formulations such as the ab-initio technique can considerably aid the design of new materials. The ab-initio Density Functional Theory (DFT) has proven a powerful tool in obtaining the structure-property relationship of a material (Hohenberg and Kohn, 1964; Kohn and Sham, 1965). DFT has been used to obtain results that have helped to predict the structure, elastic and the thermodynamic properties of many materials. The obvious advantage with DFT is cost savings. For experiments that are complicated, dangerous or expensive, DFT can serve as a cost-effective route for testing and screening new material candidates before experiments. It can provide useful information on new materials and help to tailor materials for improved applications. There are basically two theoretical approaches $-a b$ initio and molecular dynamics. Different opinion exists regarding which of the approaches gives better result. However, while the fundamental formalism behind these approaches differs, the trends are often generally independent of formalism. Despite the contribution of theoretical approaches in providing insight and good interpretation of material synthesis route, a number of mysteries still remain. This paper reviews the role that computation is capable of at complementing experimental efforts. Specifically, some alloys in which computation and experiment have shown agreements are considered. The discussion that follows includes computation (ab-initio) and the empirical methods (molecular dynamics).

\section{COMPUTATIONAL APPROACHES}

There exist several and efficient computer codes for evaluating the total energy of an ensemble of atoms using density functional theory (DFT). The ab initio DFT is more suited to ground state properties and systems with about 100 atoms or less. For larger systems of atoms, the molecular dynamics (MD) approach is preferred. However, MD comes with additional cost, as the description of its inter-atomic potentials is somewhat analytical. The other factor that determines the choice of computation approach is available computer resources. DFT is an ongoing formalism. Hence, its application to excited energy states, band gaps, etc is undergoing further developments. For the ground state properties, two variants of DFT (local density approximation (LDA) (Ceperley and Alder, 1980) and the Generalized Gradient Approximation (GGA) (Perdew et al., 1997), have shown significant relevance. While the GGA is noted to give a good description of the lattice geometry, the LDA is much better for the elastic constants. $\mathrm{A}$ number of codes, such as the Vienna $\mathrm{Ab}$ initio Simulation Package (VASP) (Kresse and Hafner, 1993), 
SIESTA (Soler et al., 2002), QUANTUM ESPRESSO (Giannozzi et al., 2009) and Wien2k (Blaha et al., 2001) have shown relevance within ab initio DFT domain. A common feature among these codes is the use of pseudopotentials (Vanderbilt, 1990) and the plane wave basis sets (Troullier and Martins, 1991; Joubert, 1998). The DLPOLY (Smith and Forester, 1996) and GULP (Gale, 1997) are representative codes for MD computation techniques. From either of the approaches, the total electronic energy $E_{t o t}$ of the system is first evaluated, after which the formation enthalpy $\Delta E^{\Theta}$ can then be deduced. For a binary system, the general expression which can be expanded for ternary and quaternary systems is of the form::

$\Delta E^{\Theta}\left(\mathrm{X}_{\mathrm{m}} \mathrm{M}_{\mathrm{n}}\right)=\frac{1}{m+n} E_{\mathrm{X}_{\mathrm{m}} \mathrm{M}_{\mathrm{n}}}^{\Theta}-\left[\frac{m}{m+n} E_{X}^{\Phi}+\frac{n}{m+n} E_{M}^{\psi}\right]$

where $E_{\mathrm{X}_{\mathrm{m}} \mathrm{M}_{\mathrm{n}}}^{\Theta}$ is the total energy of $\mathrm{X}_{\mathrm{m}} \mathrm{M}_{\mathrm{n}}$ with $\Theta$ structure, $E_{X}^{\Phi}$ is the total energy per atom of $\mathrm{X}$ with $\Phi$ structure and $E_{M}^{\psi}$ is the total energy per atom of $\mathrm{M}$ with $\psi$ structure. Negative formation energy indicates a thermodynamically feasible material, while a positive one indicates an unstable or metastable material.

The elastic constants $\left(c_{i j}\right)$ can be deduced from a variation of the total ground state energy $E$ with the unit cell distortion $x$ as given in equations (2) and (3). For a cubic structure, only three elastic constants $\left(c_{11}, c_{12}, c_{44}\right)$ are required.

$\Delta E(x)=\Delta E(-x)=V\left(c_{11}-c_{12}\right) x^{2}+\theta\left[x^{4}\right]$,

$\Delta E(x)=\Delta E(-x)=\frac{1}{2} V c_{44} x^{2}+\theta\left[x^{4}\right]$,

where $\Delta E$ is the change in energy accompany distortion $x, V$ is the crystal volume and $\theta$ is the distortion factor.

For isotropic systems, the approximate bulk and shear moduli can be evaluated, using the Voigt $\left(B_{V}, G v\right)$ (Voigt, 1928) and Reuss $\left(B_{R}, \mathrm{G}_{R}\right)$ (Reuss, 1929) expressions respectively, which are of the form:

$B_{V}=\frac{C_{11}+2 C_{12}}{3}$

$G_{V}=\frac{C_{11}-C_{12}+3 C_{44}}{5}$

$B_{R}=\frac{C_{11}+2 C_{12}}{3}$

$G_{R}=\frac{5\left(C_{11}-C_{12}\right) C_{44}}{\left[4 C_{44}+3\left(C_{11}-C_{12}\right)\right]}$
Since Voigt and Reuss expressions represent the upper and lower limits for true polycrystalline modulus, it is believed that the arithmetic mean of these moduli gives a better modulus (Hill, 1952).

The Young's modulus $E$ and Poisson's ratio $v$ can be deduced from the bulk and shear moduli according to the following equations (Green, 1993):

$E=\frac{9 B G}{3 B+G}$

$v=\frac{3 B-2 G}{2(3 B+G)}$

For isotropic materials, the bulk, or the shear modulus is believed to relate with material strength (Chen et al., 2011). The $\mathrm{G} / \mathrm{B}$ ratio relates with ductility in a material (Pugh, 1954). A material with lower $G / B$ is believed to be more ductile compared with a material with higher $\mathrm{G} / \mathrm{B}$ value. The Young's modulus has also been used theoretically to gauge rigidity/stiffness in materials while the Poisson's ratio $(v)$ is believed to relate with the nature of bond in a material. Any material with $v \leq 0.25$ is characterized by covalent bonding and $v \geq 0.25$ would characterize any material in which ionic bond dominates (Bannikov et al., 2007). A material, whose shape can withstand an external force is said to be mechanically stable. The established stability criteria for the cubic and a number of crystal systems (Born and Huang, 1954) are:

$c_{11}-c_{12}>0 ; c_{11}+2 c_{12}>0 ; c_{11}>0 ; c_{44}>0$

The stability criteria for a tetragonal system are:

$\left(c_{11}+c_{33}-2 c_{13}\right)>0 ; c_{11}-c_{12}>0 ; c_{11}>0 ; c_{44}>0$;

$c_{33}>0 ; c_{66}>0 ;\left(2 c_{11}+c_{33}+2 c_{12}+4 c_{13}\right)>0$

The stability criteria for the orthorhombic system are:

$$
\begin{gathered}
\left(c_{11}+c_{22}-2 c_{13}\right)>0 ; c_{11}-c_{12}>0 ; c_{11}>0 ; c_{22}>0 ; \\
\left(c_{11}+c_{33}-2 c_{13}\right)>0 ; c_{33}>0 ; c_{44}>0 ; \\
\left(c_{11}+c_{22}+c_{33}+2 c_{12}+2 c_{13}+2 c_{23}\right)>0 \\
\left(c_{22}+c_{33}-2 c_{23}\right)>0 ; c_{55}>0 ; c_{66}>0
\end{gathered}
$$

The stability criteria for the tetragonal system are:

$$
\begin{gathered}
c_{11}+c_{12}-\frac{2 c_{13}^{2}}{c_{33}}>0 ; \\
c_{66}=\frac{c_{11}+c_{12}}{2}>0 ; c_{44}>0
\end{gathered}
$$


Nigeria Journal of Pure \& Applied Physics, Vol. 8, No. 1, pages 40-47, 2018

The Density of States (DOS) describes the number of states per interval of energy available for electron occupation. For an electron gas, the density of states can be expressed as:

$N(E)=\frac{1}{2 \pi^{2}}\left(\frac{2 m}{\hbar^{2}}\right)^{\frac{3}{2}} E^{\frac{1}{2}}$

where $E$ is the energy of each electronic state, $\hbar$ is the planck's constant, $m$ is the mass of particles at each energy level and $N(E)$ is the density of states. Material types (i.e. conductor, semiconductor etc) and other electronic properties such as phase stability and bonding can be deduced from DOS histograms. The sampling algorithm for DOS calculations is often an integral part of DFT codes.

Materials that change phase due to temperature or pressure variation are said to be metastable. The dynamic process responsible for this phenomenon is somehow subtle and therefore, the transition pressure between the phases involved is evaluated. The indicator often used is the difference between the energy of the phases. A very small difference would imply that a low transition pressure is needed between different phases.

\section{Strong Intermetallic Compounds}

Many new materials have been suggested with some already synthesized. The properties of $\mathrm{Ni}_{3} \mathrm{Al}$ are well known - it has excellent ductility and positive temperaturestrength relationship up to its melting point (Aoki and Izumi, 1979; Sims et al., 1987; Dey and Sekhar, 1987; Briant et al., 1993). Present day superalloys rely on the precepts of $\mathrm{Ni}_{3} \mathrm{Al}$. Platinum metal alloys have received considerable attention and have been promoted to replace $\mathrm{Ni}_{3} \mathrm{Al}$ due to higher melting point and environmental stability (Yamabe-Mitarai et al., 2004; Cornish et al., 2002). The most stable platinum based binary alloys are $\mathrm{Pt}_{3} \mathrm{Sc}, \mathrm{Pt}_{3} \mathrm{Hf}, \mathrm{Pt}_{3} \mathrm{Zr}$ and $\mathrm{Pt}_{3} \mathrm{Al}$. The synthesis, phase stability and thermodynamic properties of these materials are well documented (Dwight and Conner, 1961; Bronger and Klemm 1962; Huch and Klemm, 1964; Chattopadhyay and Schubert 1975; Pecora and Ficalora, 1977). While $\mathrm{Pt}_{3} \mathrm{Sc}$ has the cubic $c P 4-\mathrm{Cu}_{3} \mathrm{Au}\left(L 1_{2}\right)$ phase similar to $\mathrm{Ni}_{3} \mathrm{Al}$, both the $L 1_{2}$ and $D 0_{24}$ phases have been reported in $\mathrm{Pt}_{3} \mathrm{Hf}$ and $\mathrm{Pt}_{3} \mathrm{Zr}$ (Massalski et al., 1990 and Villars et al., 2004). $\mathrm{Pt}_{3} \mathrm{Al}$ is believed to have the $L 1_{2}$ cubic structure at hightemperature but tetragonal structures at lower temperatures (Villars et al., 2004). Another version of available result (McAlister and Kahan, 1986) showed that the cubic $c \mathrm{P} 4$ $\mathrm{Cu}_{3} \mathrm{Au}\left(L 1_{2}\right)$ phase of $\mathrm{Pt}_{3} \mathrm{Al}$ would transform to the tetragonal $t \mathrm{P} 16-\mathrm{Pt}_{3} \mathrm{Ga}$ structure at around $1290^{\circ} \mathrm{C}$. Another result version (Oya et al., 1987) had argued that two transformations; the $L 1_{2}$ phase transforming to the $t \mathrm{I} 16$ $\mathrm{U}_{3} \mathrm{Si} \quad\left(\mathrm{D}_{c}\right)$ structure at $420^{\circ} \mathrm{C}$ before another transformation at $130^{\circ} \mathrm{C}$ to the $t \mathrm{I} 16-\mathrm{Ir}_{3} \mathrm{Si}\left(\mathrm{D}_{c}^{\prime}\right)$ structure in contrast to the report of McAlister and Kahan (1986). While $\mathrm{Ni}_{3} \mathrm{Al}$ has an excellent ductility at room temperature, the ductility of $\mathrm{Pt}_{3} \mathrm{Al}$ is very low at room temperature due to the phase transformations (Cornish et al., 2003).

The ground state electronic energy, $E_{0}$, in Table 1 for all competing structures can help resolve the uncertainties surrounding the true structure of these compounds at the ground state.

Table 1: Calculated bulk modulus $(B)$, shear modulus $(G)$, $\mathrm{G} / B$ ratio, Poisson's ratio $(v)$, equilibrium energy $\left(E_{0}\right)$, and density $(\rho)$ for $\mathrm{Pt}_{3} \mathrm{Al}, \mathrm{Pt}_{3} \mathrm{Sc}, \mathrm{Pt}_{3} \mathrm{Zr}$ and $\mathrm{Pt}_{3} \mathrm{Hf}$. Experimental data are in brackets and are from Pecora and Ficalora, (1977)

$\begin{array}{llllllll}\text { Alloy } & \text { Structure } & B & G & G / B & v & \begin{array}{l}E_{0} \\ (\mathrm{eV} / \mathrm{at} .)\end{array} & \rho\left(\mathrm{g} \cdot \mathrm{cm}^{-3}\right) \\ & & & & & & \\ \mathrm{Pt}_{3} \mathrm{Sc} & L 1_{2} & 250 & 103 & 0.41 & 0.29 & -7.178 & 12.36 \\ \mathrm{Pt}_{3} \mathrm{Al} & L 1_{2} & 280 & 108 & 039 & 0.30 & -6.256 & 12.24 \\ & \mathrm{D} 0_{c}^{\prime} & 309 & 98 & 0.32 & 0.30 & -6.297 & 12.68 \\ & t P 16- & 378 & 71 & 0.19 & 0.34 & -6.354 & 12.68 \\ & \mathrm{Pt}_{3} \mathrm{Ga} & & & & & & \\ \mathrm{Pt}_{3} \mathrm{Hf} & L 1_{2} & 290 & 120 & 0.41 & 0.28 & -8.129 & 18.88 \\ & \mathrm{D}_{24} & 151 & 111 & 0.74 & 0.31 & -8.135 & 19.59[19.62] \\ \mathrm{Pt}_{3} \mathrm{Zr} & L 1_{2} & 282 & 113 & 0.40 & 0.29 & -7.693 & 14.31 \\ & \mathrm{D}_{24} & 280 & 106 & 0.38 & 0.31 & -7.701 & 16.96[18.13]\end{array}$

From the $E_{0}$ results (see Table 1 ), the $\mathrm{D}_{24}$ is theoretically predicted to be the ground state structure of $\mathrm{Pt}_{3} \mathrm{Hf}$ and $\mathrm{Pt}_{3} \mathrm{Zr}$. Their $E_{0}$ in this phase is lower compared with that of the $L 1_{2}$ phases. For similar reasons, the ground state structure of $\mathrm{Pt}_{3} \mathrm{Al}$ should be the $t P 16-\mathrm{Pt}_{3} \mathrm{Ga}$ which also agrees with other theoretical results (Chauke et al., 2010). The Vickers microhardness for $\mathrm{D}_{24}-\mathrm{Pt}_{3} \mathrm{Hf}$ and $\mathrm{D0}_{24}-\mathrm{Pt}_{3} \mathrm{Zr}$ is $796 H_{V}$ and $811 H_{V}$ respectively (Pecora and Ficalora, 1977). A clear correlation is seen between these values and the bulk modulus - $\mathrm{D0}_{24}-\mathrm{Pt}_{3} \mathrm{Zr}$ has a higher bulk modulus (B) than $\mathrm{D0}_{24}-\mathrm{Pt}_{3} \mathrm{Hf}$. Thus, a reasonable prediction would mean that the hardest alloy is $\mathrm{Pt}_{3} \mathrm{Al}$ in the $t P 16-\mathrm{Pt}_{3} \mathrm{Ga}$ phase, followed by $\mathrm{D0}_{24}-\mathrm{Pt}_{3} \mathrm{Zr}$, then $L_{2}-\mathrm{Pt}_{3} \mathrm{Sc}$ and lastly $\mathrm{DO}_{24}-\mathrm{Pt}_{3} \mathrm{Hf}$. 

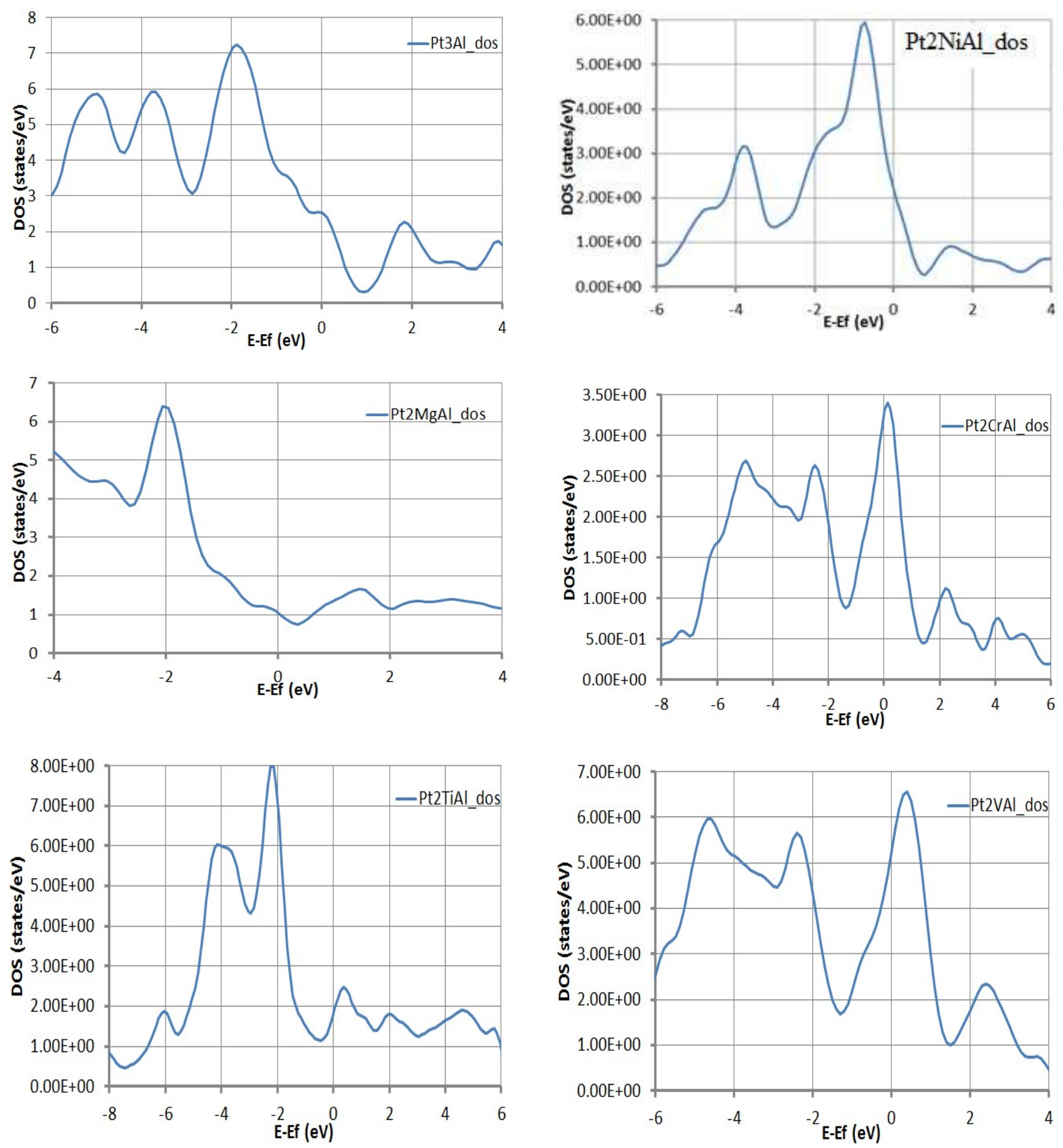

Figure 1: Total density of states for $\mathrm{Pt}_{3} \mathrm{Al}, \mathrm{Pt}_{2} \mathrm{CrAl}, \mathrm{Pt}_{2} \mathrm{MgAl}, \mathrm{Pt}_{2} \mathrm{NiAl}, \mathrm{Pt}_{2} \mathrm{TiAl}_{\mathrm{A}}$ and $\mathrm{Pt}_{2} \mathrm{VAl}$ 
A ductile material should show correlation with low $G / B$ $(G / B \leq 1.06)$ or high $v$. Based on this, the most ductile alloy would be $\mathrm{Pt}_{3} \mathrm{Al}$ in the $t P 16-\mathrm{Pt}_{3} \mathrm{Ga}$ phase, followed by $\mathrm{D}_{24}-$ $\mathrm{Pt}_{3} \mathrm{Zr}, \mathrm{L1}_{2}-\mathrm{Pt}_{3} \mathrm{Sc}$ and lastly $\mathrm{D0}_{24}-\mathrm{Pt}_{3} \mathrm{Hf}$. With regards to density, $\mathrm{Pt}_{3} \mathrm{Al}$ and $\mathrm{Pt}_{3} \mathrm{Sc}$ are less dense compared to $\mathrm{Pt}_{3} \mathrm{Zr}$ and $\mathrm{Pt}_{3} \mathrm{Hf}$ and could be more preferred for space based applications.

The superalloy $\mathrm{Pt}_{3} \mathrm{Al}$, has proved an interesting material for both ab-initio (Yu et al., 2004; Chauke et al., 2010; Wei et al., 2015) and molecular dynamic (MD) simulations. The density of $\mathrm{Pt}_{3} \mathrm{Al}$ is about $16 \mathrm{~g} / \mathrm{cm}^{3}$ and this has limited its wide use. The DOS could be a versatile tool at evaluating the prospect of weight reduction in $\mathrm{Pt}_{3} \mathrm{Al}$. An extract from the work of Popoola (2019), shows that weight reduction can be achieved in $\mathrm{Pt}_{3} \mathrm{Al}$ when $\mathrm{Pt}$ is partly or wholly substituted with light weight elements. While good weight reduction will be achieved, tremendous impact would also occur on the electronic structure. For a better understanding, figure 1 show that substituting about $33 \%$ of $\mathrm{Pt}$ in $\mathrm{Pt}_{3} \mathrm{Al}$ with $\mathrm{Cr}$, Ti or $\mathrm{V}$ will be counterproductive. The DOS at $\mathrm{E}-\mathrm{E}_{\mathrm{F}}=0$ for $\mathrm{Pt}_{2} \mathrm{CrAl}, \mathrm{Pt}_{2} \mathrm{TiAl}$ and $\mathrm{Pt}_{2} \mathrm{VAl}$ are found to be higher or falls on the anti-bonding side of the spectrum compared to $\mathrm{Pt}_{3} \mathrm{Al}$. The DOS results for $\mathrm{Pt}_{2} \mathrm{MgAl}$ and $\mathrm{Pt}_{2} \mathrm{NiAl}$ shows that $\mathrm{Mg}$ and $\mathrm{Ni}$ could be beneficial at creating additional stability when about $33 \%$ of $\mathrm{Pt}$ in $\mathrm{Pt}_{3} \mathrm{Al}$ is substituted with these elements. It is noted that the DOS is lower for the compounds and at $\mathrm{E}-\mathrm{E}_{\mathrm{F}}=0$, the Fermi level is on the nonbonding side of the energy spectrum. Melting phenomena can be easily studied with MD and the SuttonChen-Tabar potentials (Sutton and Chen 1990; Rafii-Tabar and Sutton, 1991; Rafii-Tabar, 2000) seem quite good with results that agree with experiment. A typical result from such calculation (see Figure 2) shows atom distribution with temperature. At $\mathrm{T}=0 \mathrm{~K}$, the atomic composition of $\mathrm{Pt}_{3} \mathrm{Al}$ was distinct and orderly (Fig. 2a(i)). At a temperature of $1000 \mathrm{~K}$, some disorderliness are seen in the lattice of $\mathrm{Pt}_{3} \mathrm{Al}$ (Fig. 2a(ii)), which predicts slight deformation in its cubic lattice. At $2000 \mathrm{~K}$, a temperature well above the melting point of $\mathrm{Pt}_{3} \mathrm{Al}(1829 \mathrm{~K})$, no sign of cubic lattice is evident (Fig. 2a(iii)), predicting that the material has melted.

Additional understanding regarding melting phenomena can also be gained from the Diffusion Coefficient (DCo) and Radial Distribution Function (RDF) analysis. The RDF basically provides information regarding the melting point, while the DCo will give information on the melting point as well as the relative melting of the constituents. Using the $\mathrm{RDF}$, the melting point is deduced by monitoring where a drastic change in the shape of the RDF has occurred. For
$\mathrm{Pt}_{3} \mathrm{Al}$ (Fig. 2b(ii)), drastic change occurred between $1890 \mathrm{~K}$ and $1900 \mathrm{~K}$. The melting point on the DCo plot (Fig. 2b(i)) can be identified with a discontinuity or jump and this occurred between $1890 \mathrm{~K}$ and $1900 \mathrm{~K}$. It can also be predicted from the plot that Al has a slightly higher DCo than $\mathrm{Pt}$ - meaning that $\mathrm{Al}$ will start melting before $\mathrm{Pt}$ in $\mathrm{Pt}_{3} \mathrm{Al}$. The two results (RDF and DCo) show that the melting of $L 1_{2}-\mathrm{Pt}_{3} \mathrm{Al}$ is between $1890 \mathrm{~K}$ and $1900 \mathrm{~K}$. This prediction is about $4 \%$ away from the experimental melting point of $L 1_{2}-\mathrm{Pt}_{3} \mathrm{Al}$, which melts at $1829 \mathrm{~K}$.

\section{CONCLUSION}

The development in technology has been characterized by breakthroughs in the science and engineering of materials. As we search for new and better materials, efforts must be geared at optimally utilizing available tools - theory and experiment. With the emergence of fast computers and bug-free codes, many aspect of a material can be understood before the actual laboratory experiment. The information derivable from theoretical investigations is numerous. It has been demonstrated how the internal ground state energy can be used to determine the structure/material phase with better chance for existence. A thermodynamically feasible material can also be determined by simply calculating the internal energy of a structure, relative to its atomic components. Also, investigating the electronic band structure such as the density of states can provide fundamental information relating to the type and nature of the bond in a material. It is a common knowledge that the type of bond and its character in a material determines a number of properties including; mechanical, electrical and sometimes optical.

Materials behave differently under different conditions. To take care of this, the two main theoretical techniques $\mathrm{ab}$ initio and molecular dynamics have also undergone improvements. While the ab-initio method has proved reliable for ground state properties, the molecular dynamics is more suitable for large ensembles, particularly at finite temperatures. The difficulty at the moment, as revealed by the discussed result on $\mathrm{Pt}_{3} \mathrm{Al}$ is how to extend the ab initio into the same region as the MD. Despite this challenge, the use of theory to complement experimental efforts has been known to save cost and shorten timely delivery of end products. Given the achievements already recorded and the various trend of results discussed, the relevance of computation techniques in materials development will continue to gain unprecedented attention and the progress will likely continue unabated. 


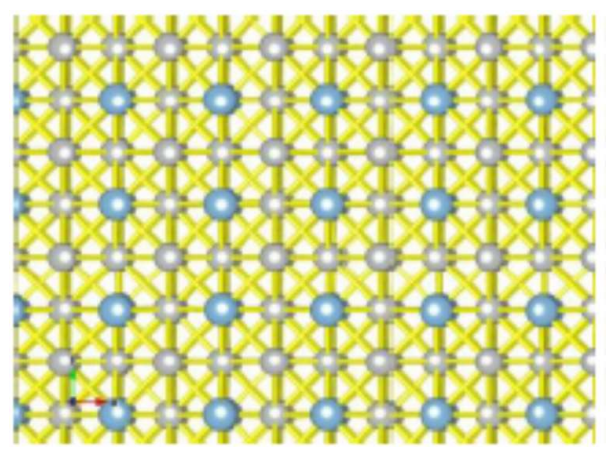

a(i)

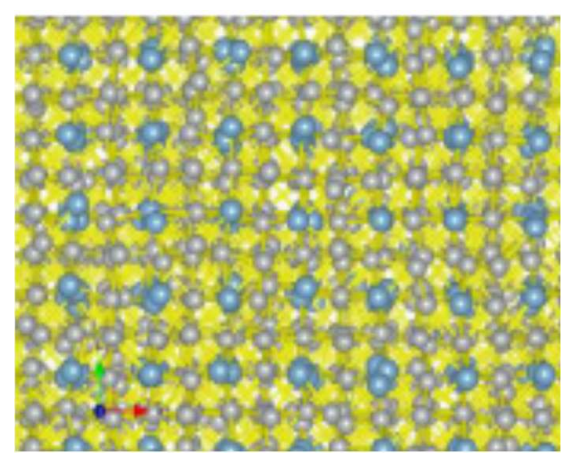

a(ii)

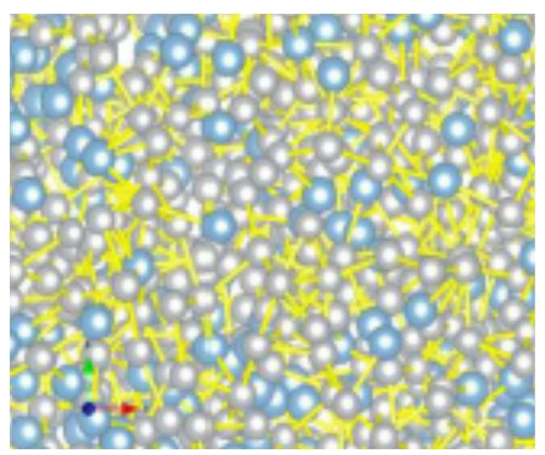

a(iii)
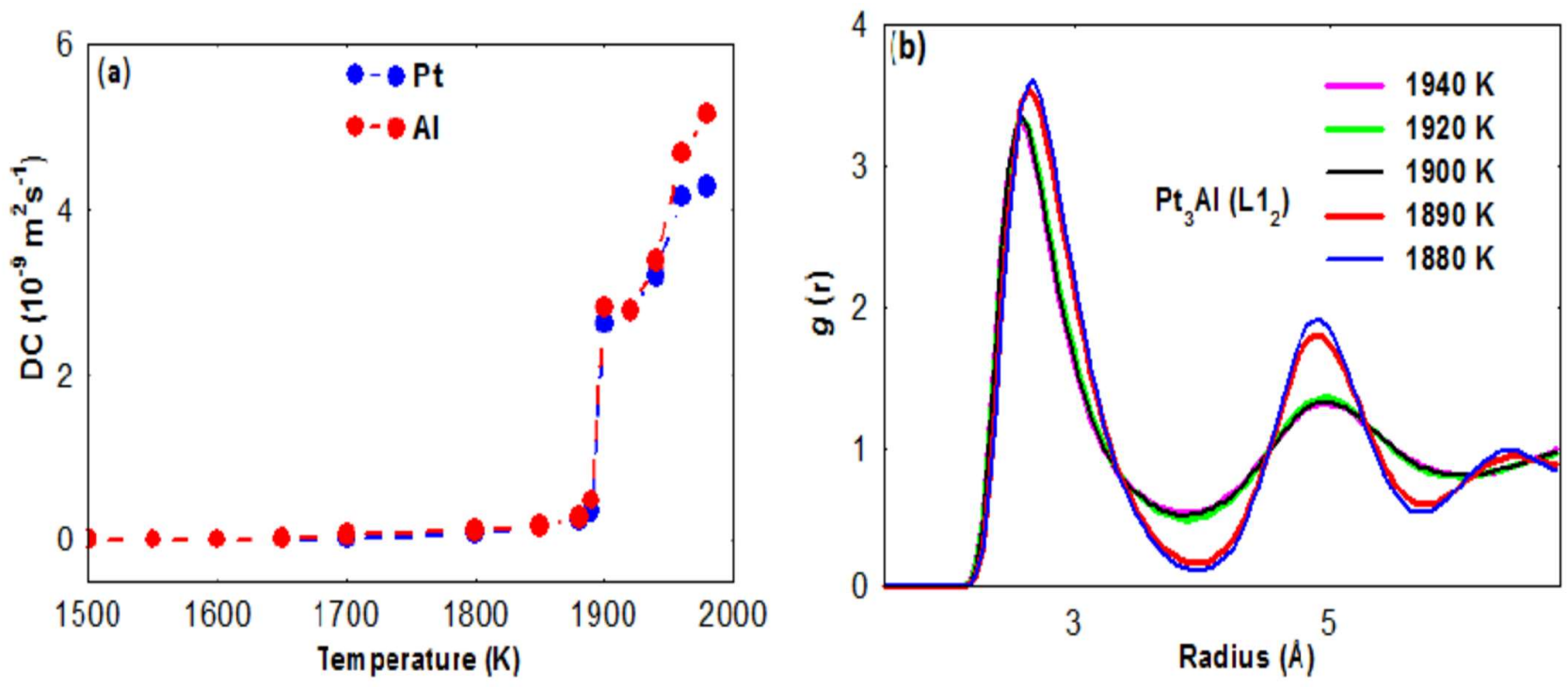

Figure 2. Molecular Dynamics results for the melting of $\mathrm{Pt}_{3} \mathrm{Al}$. a(i): $\mathrm{Pt}_{3} \mathrm{Al}$ structure at $\mathrm{T}=0 \mathrm{~K}$; $\mathrm{a}(\mathrm{ii}): \mathrm{Pt}_{3} \mathrm{Al}$ structure at $\mathrm{T}=1000$ $\mathrm{K}$ and $\mathrm{a}$ (iii): $\mathrm{Pt}_{3} \mathrm{Al}$ structure at $\mathrm{T}=2000 \mathrm{~K} ; \mathrm{b}$ (i): $\mathrm{Pt}_{3} \mathrm{Al}$ diffusion coefficient plot and $\mathrm{b}(\mathrm{ii}): \mathrm{Pt}_{3} \mathrm{Al}$ radial distribution function plot 


\section{REFERENCES}

1) Aoki K. and Izumi O. 1979. Flow and fracture behaviour of $\mathrm{Ni}_{3}(\mathrm{Al} \cdot \mathrm{Ti})$ single crystals tested in tension. Journal of Materials Science 14(8), 1800 $-1806$.

2) Bannikov V. V., Shein I. R. and Ivanovskii A. L. 2007. Electronic structure, chemical bonding and elastic properties of the first thorium-containing nitride perovskite $\mathrm{TaThN}_{3}$. Phys. stat. sol. (RRL) 1(3), $89-91$.

3) Blaha P., Schwarz K., Madsen G. K. H., Kvasnicka D. and Luitz J. 2001. WIEN2K, An Augmented Plane Wave + Local Orbitals Program for Calculating Crystal Properties.

4) Born M. and Huang K. 1954. Dynamical Theory of Crystal Lattices, Oxford University Press, London.

5) Briant C.L., Petrovic J. J., Bewlay B.P., Vasudevan A.K. and Lipsitt H.A. (Eds.). 1993. High Temperature Silicides and Superalloys. Materials Research Society Symposium Proceedings, Boston, Massachusetts, U.S.A.

6) Bronger W. and Klemm W.Z. 1962. Darstellung von Legierungen des Platins mit unedlen Metallen.Anorg. allg. chem., 319, 58-81. doi:10.1002/zaac.19623190110.

7) Ceperley D.M. and Alder B.J. 1980. Ground state of the electron gas by a stochastic method. Phys. Rev. Lett. 45, 566-568.

8) Chattopadhyay T. and Schubert K. 1975. Kristallstruktur von $\mathrm{Pt}_{3} \mathrm{Ga}(\mathrm{r})$ und einigen Phasen der Mischung Pt-A1. J. Less-Common Met., 41, 19-32.

9) Chauke H .R., Minisini B., Drautz R., NguyenManh D., Ngoepe P. E. and Pettifor D. G.2010. Theoretical investigation of the $\mathrm{Pt}_{3} \mathrm{Al}$ ground state. Intermetallics. 18, 417-421.

10) Chen X. Q., Niu H. Y., Li D. Z. and Li Y. Y. 2011. Modeling hardness of polycrystalline materials and Bulk metallic glasses. Intermetallics, 19, 1275-1281.

11) Cornish L.A., Hohls J., Hill P.J., Prins S., Sűss R. and Compton D.R. 2002. The development of platinum-based alloys and their thermodynamic database. Journal of Mining and Metallurgy 38 (3†4) B, $197-204$.

12) Cornish L. A., Fischer B. and Völkl R. 2003. Development of Platinum-Group-Metal
Superalloys for High-Temperature Use. MRS Bull. 28(9), 632-638.

13) Dey G.K.and Sekhar, J.A. 1987. Physical metallurgy of nickel aluminides. Metallurgical and Materials Transaction B 28, 905-909

14) Dwight A. E. and Conner jr R. A. 1961. Some $\mathrm{AB}_{3}$ compounds of the transition metals. Acta Crystallogr., 14, 75 -76.

15) Gale J.D. 1997. Gulp: A computer program for the symmetry-adapted simulation of solids. J. Chem. Soc. Trans. 1, 629-641.

16) Giannozzi P., Baroni S., Bonini N., Calandra M., Car R., Cavazzoni C., Ceresoli D., Chiarotti G. L., Cococcioni M., Dabo I., Dal Corso A., Fabris S., Fratesi G., De Gironcoli S., Gebauer R., Gerstmann U., Gougoussis C., Kokalj A., Lazzeri M., Martin-Samos L.,Marzari N., Mauri F., Mazzarello R., Paolini S., Pasquarello A.,Paulatto L., Sbraccia C.,Scandolo S., Sclauzero G., Seitsonen A. P., Smogunov A., Umari P. and Wentzcovitch R. M.2009. Journal of Physics Condensed Matter.21, 395502.

17) Green D. J. 1993. An Introduction to the Mechanical Properties of Ceramics, Cambridge University Press, Cambridge.

18) Hill R. 1952. Proc. Phys. Soc., Sect. A, 65: 349 354.

19) Hohenberg P. and Kohn W. 1964. Inhomogeneous Electron Gas. Physical Reviews B 136, 864 - 875.

20) Huch R. and Klemm W.Z. 1964. Das System Platin-Aluminium. Z. anorg. allg. Chem., 329, 123 -135. doi:10.1002/zaac.19643290116.

21) Joubert D.P. 1998. Density Functional Theory. Springer: Heidelberg, Germany.

22) Kohn W. and Sham L. J. 1965. Self-Consistent Equations Including Exchange and correlation effects. Physical Reviews A 140, 1133-1139.

23) Kresse G. and Hafner J. 1993. Ab initio molecular dynamics for liquid metals. Phys. Rev. B 47, 558563.

24) Massalski T. B., Okamoto H., Subramanian P. R. and KacprzakL. eds. 1990. Binary Alloy Phase Diagrams (American Society for Metals, Materials Park, OH).

25) McAlister A. J. and Kahan D. J. 1986. The Al-Pt (Aluminum-Platinum) system. Bull Alloy Phase Diagr., 7(1), 47 - 51.

26) Oya Y., Mishima Y. and Suzuki T. 1987.L1 $1_{2} \Leftrightarrow \mathrm{D} 0_{\mathrm{c}}$ martensitic transformation in $\mathrm{Pt}_{3} \mathrm{Al}$ and $\mathrm{Pt}_{3} \mathrm{Ga}$. Z. Metallkde, 78(7), 485-490. 
27) Pecora L. M. and Ficalora P. J. 1977. Some bulk and thin film properties of $\mathrm{Pt}_{3} \mathrm{Zr}$ and $\mathrm{Pt}_{3} \mathrm{Hf}$ Journal of Electronic Materials 6, 531-540.

28) Perdew J.P. and Kurth S. 1997. Density Functionals: Theory and Applications; Theoretical Physics Conference held at Meerensee, Cape Town, South Africa, volume 8.

29) Popoola A. I. 2019. Effect of Substituting Pt with $\mathrm{X}(\mathrm{X}=\mathrm{Mg}, \mathrm{V}, \mathrm{Ni}, \mathrm{Cr}, \mathrm{Ti})$ on the Electronic Properties of $\mathrm{Pt}_{3} \mathrm{Al}$ and $\mathrm{Pt}_{3} \mathrm{Sc}$. FUTA Jour. of Reserch in Sci. 15(1), 85-95.

30) Pugh S. F. 1954. Philos. Mag. 45, 823 - 843

31) Rafii-Tabar H. and Sutton A.P. 1991. Long-range Finnis-Sinclair Potentials for f.c.c. Metallic Alloys. Philosophical Magazine Letters 63, 217234.

32) Rafii-Tabar H. 2000. Modeling the nano-scale phenomena in condensed matter physics via computer-based numerical simulations. Physics reports 325, $239-310$.

33) Reuss A. and Angew Z. 1929. Math. Mech. 9, 4958

34) Sims C.T., Stoloff N.S. and Hagel, W. C. (Eds.). 1987. Superalloys II. New York, Wiley InterScience.

35) Smith W. and Forester T. 1996. DLPOLY code for molecular dynamics. J. Mol. Graph. 14, 136142.

36) Soler J.M., Artacho E., Gale J.D., Garcia A., Junquera J., Ordejon P. and Sanchez-Portal D. 2002. The SIESTA method for ab initio order-N materials simulation. J. Phys. Condens. Matter 14, 2745-2779.

37) Sutton A.P. and Chen J. 1990. Long-range FinnisSinclair Potentials. Philos. Mag. Lett., 61,139146.

38) Troullier N. and Martins J.L. 1991. Efficient pseudopotentials for plane-wave calculations.

Phys. Rev. B 43, 1993-1997.

39) Vanderbilt D. 1990. Soft self-consistent pseudopotentials in generalized eigenvalue formalism. Phys. Rev. B 41, 7892-7895

40) Villars P., Berndt M., Brandenburg K., Cenzual K., Daams J., Hulliger F., Massalski T., Okamoto H., Osaki K., Prince A., Putz H. and Iwata S. 2004. The Pauling File, Binaries Edition. J. Alloys Compound 367, 293-297.

41) Voigt W. 1928. Lehrbuch der Kristallophysic, Teuber, Leipzig.

42) Wei N., Zhang Ch. and Hou S. 2015. Theoretical study of the elastic and thermodynamic properties of $\mathrm{Pt}_{3} \mathrm{Al}$ with the $\mathrm{L}_{2}$ structure under high pressure. Condensed Matter Physics, 18(4), 43601: 1-8

43) Yamabe-Mitarai Y., Gu Y., Huang C., Volki R. and Harada H. 2004. Platinum-group-metal-based intermetallics as high-temperature structural materials. Journal of Materials Chemistry 56, 3442.

44) Yu O., Gornostyrev N., Kontsevoi A. F., Maksyutov A. J., Freeman M. I., Katsnelson A. V. and Lichtenshtein A.I. 2004. Negative yield stress temperature anomaly and structural instability of $\mathrm{Pt}_{3}$ Al. Physical Review B 70, 014102, 